\title{
Peer Learning, Self-Regulated Learning and Academic Achievement in Blended Learning Courses: A Structural Equation Modeling Approach
}

\author{
https://doi.org/10.3991/ijet.v15i03.12031 \\ Chee Leong Lim ${ }^{(凶)}$ \\ Taylor's University, Subang Jaya, Malaysia \\ University Putra Malaysia, Serdang, Malaysia \\ cheeleong.lim@taylors.edu.my \\ Habibah Ab Jalil, Aini Marina Ma'rof, Wan Zuhainis Saad \\ University Putra Malaysia, Serdang, Malaysia
}

\begin{abstract}
The ability for students to self-regulate their learning and to learn effectively with peers become two distinctive competencies in the era of the 4th Industrial Revolution. These competencies also affect academic achievement, an important variable used to measure attainment of learning outcomes. Therefore, this study was conducted to determine the influence of peer learning and selfregulated learning (SRL) strategies on students' academic achievement. Of the 409 respondents, only 347 were valid for data analysis, forming a usable case of $84.84 \%$. The instruments used was an online questionnaire, which was adapted from pre-existing reliable multi-item instruments. Structural Equation Model (SEM) analysis was used to examine the relationship between the constructs in the hypothesised model. Given that the structural model exhibited a good fit to the data $(\chi 2 / \mathrm{df}=1.697 ; \mathrm{CFI}=0.916 ; \mathrm{IFI}=0.917 ; \mathrm{TFI}=0.912 ;$ and $\mathrm{RMSEA}=$ $0.045)$, the results unveiled that students' ability to learn with peers were found to have a positive and significant effect on academic achievement $(\beta=0.478$, C.R. $=3.628, p=0.000)$, and significantly influenced students' SRL strategies ( $\beta$ $=0.793 ;$ C.R. $=6.991 ; p=0.000)$. This study also discusses the practical implications to facilitate the development of students' self-regulated learning (SRL) and peer learning competencies in blended learning courses.
\end{abstract}

Keywords - Self-regulated learning (SRL); peer learning; academic achievement; blended learning; Structural Equation Modeling (SEM).

\section{Introduction}

Perceptions of blended learning have been shifting in its favour over the past several years. Blended learning continues to be a popular format for educational experiences because of its flexibility and customizability to students' needs [1]. Blended learning involves the delivery which incorporates multiple modes and commonly of different modes of delivery as a result of embracing technology combined with the best features 
of face to face interaction [2]. It is also commonly referred as the organic combination of online learning and offline learning [3].

In Malaysia, due to the strong government initiatives and the rising of smartphone and tablet users in the country, the online education market is anticipated to project a promising CAGR of $16.4 \%$ from 2016-2023 [4]. Malaysia government is constantly taking initiatives to promote education through an online platform in order to increase the adoption of technology among the young generation. For instance, the MOOC initiative aimed to narrow the educational inequality by offering high quality and affordable learning opportunities to all as long as they have Internet connectivity. This accessible and convenient online education platform also helps to overcome the shortage of quality education in the country and further propel the blended learning growth at an ever-increasing rate. With such a spike in the educational technology solutions, educators can transform their online learning practices and improve students learning to help them to face the future, especially under the context of higher education in the fourth industrial age.

In the age of Fourth Industrial Revolution, the Malaysian government has urged the universities to constantly reimagine and redesign pedagogy for the 21 st-century education. This transformation in learning is crucial to equip today's learners with critical thinking, creativity, communication and collaboration skills that meet the needs of a 21 st-century marketplace. This is also aligned with the emergence of a global movement that calls for a new model of learning, which has been argued that formal education needs to be transformed to enable new forms of learning that are needed to tackle complex global challenges [5]. As such, universities in the 21 st century need to take more proactive roles in creating more opportunities that produce future-ready graduates who are more agile, have a solid understanding of how the workplace works and can see how their skills fit into it.

\subsection{Self-regulated learning}

Over the last two decades, SRL has become one of the major areas in educational research and has been addressed in various research areas, including in different modes of blended learning environments. It is an integrated learning process guided by a set of motivational beliefs, as well as behavioural, cognitive and metacognitive activities that are planned and adapted to support the pursuit of personal goals [6]. SRL is referred to as the degree to which students are metacognitively, motivationally, and behaviourally active participants in the process of monitoring their own learning. Pintrich [7] defines SRL learners as those who actively construct their own learning process and are able to set their learning goals, while also making an effort to observe, adjust, and control their cognition, motivation, and behaviour in achieving those goals.

SRL is a vital element for developing students' successful learning experiences in the delivery of online instruction for blended learning courses [8]. Students who engaged in more online self-regulatory learning behaviours generally had a more positive perception of blended courses. This is because during online instruction, students assume greater responsibility and autonomy for their learning. When they acquire the skills to regulate different learning strategies in their learning process, they will have 
greater satisfaction in learning, and hence higher chances of being successful in blended learning courses. In sum, this research focuses on how self-regulation is related to cognitive (achievement) dimension of learning outcomes in their blended courses.

\subsection{Peer learning}

Peer learning is growing internationally as a beneficial pedagogical strategy in conceptualizing learning and teaching in the global classroom [9]. Peer learning is seen as one of the richest learning resources by many researchers [10] as it is academically and socially integrated into higher education culture. In addition, peer learning plays an effective role in universities and colleges as it aids students to believe in their own abilities and be responsible for their own learning [11].

Peer-learning is defined by Topping [10] as "the acquisition of knowledge and skill through active helping and supporting among status equals or matched companions. According to Boud [12], the term "peer learning" suggests a two-way, reciprocal learning which involves notions of interdependence and mutual beneficial where students share knowledge, ideas and experience in a setting which is often constructed by the students themselves.

Extensive recent literature surroundings online peer learning found that peer learning not only gives students an opportunity to share ideas and knowledge, but also encourages them to communicate, practise and work together with peers [13]. This is affirmed by studies which revealed the importance of peer group influence and social competencies with peers in affecting the academic achievement of students [14].

\section{$2 \quad$ Literature Review}

\subsection{Peer learning and academic achievement}

Studies on the various kinds of peer learning suggested that there was a positive and significant relationship between the ability to learn with peers and their academic achievement. This was highlighted recently in the Student Online Learning Readiness (SOLR) model which was developed by $\mathrm{Yu}$ and Richardson [15]. In this model, the ability to learn with peers is highly associated with academic learning outcomes. This positive relationships between peer learning and learning achievements have also been verified in previous research by Shen et al. [16].

Similarly, studies on the various kinds of peer learning also suggested a positive and significant relationship between peer group influence and academic achievement of students. For instance, Uzezi and Deya [14] found that students who are capable of working in groups and learning with peers performed better when studying in science courses. The findings were in line with other previous findings by Bankole and Ogunsakin [17] who asserted that peer learning boosted academic achievements of all members in a class because students who are in the same class will have more opportunities to study together, and this collaborative learning behaviour helps to improve their academic achievements. 
In line with the importance of peer learning in the blended learning environment, Chen et al. [18] found that peer learning and academic achievement had cumulative reciprocal effects on each other in their 5-year longitudinal study with Chinese children. The importance of the ability to learn with peers was also proven in distance learners' academic achievement [18]. For these reasons, higher educations are urged to pay more attention to peer learning in order to maximize the effectiveness of peer learning, thus improving academic performance when they are studying online. Based on the above studies, the current study hypothesized that peer learning directly influences students' academic achievement in blended learning courses.

H1: Peer learning influences students' academic achievement in blended learning courses.

\subsection{Peer learning and self-regulated learning (SRL)}

Social cognitive theorists emphasize that learning is most effective when peer learns from others who are both similar to themselves and display high levels of self-efficacy [19]. Social cognitive perspective also provides several arguments about how students can acquire SRL skills when learning from peers [20]. More specifically, research has shown that SRL skill levels will increase when students with low self-efficacy beliefs for SRL learn from peers who exhibit high-level SRL skills. In short, students acquire SRL skills during the process of peer learning.

Students acquire SRL skills during the peer learning process because several aspects of peer learning provide mechanisms for them to acquire SRL skills. For instance, peer learning provides more opportunities for peer-to-peer interactions as compared to teacher-student interactions. Asking for help from peers often encourage students to practice self-regulatory skills such as self-reflection. Another aspect is related to shared responsibility. The general belief is that during the peer learning process, students distribute and share thinking responsibilities. Shared responsibility for thinking is an active activity and requires students to regulate their learning by using learning strategies such as help-seeking [20] and attempting to understand the thoughts of others during task performance. Based on these studies, the current study hypothesized that peer learning directly influences students' self-regulated learning (SRL) ability.

$\mathrm{H}_{2}$ : Peer learning influences students' self-regulated learning (SRL) strategies in blended learning courses.

\subsection{Self-regulated learning (SRL) and academic achievement}

The literature review has suggested that SRL as a mechanism to help explain differences in academic achievements among students and use SRL as a means to improve achievement [19]. Research findings have proven that SRL strategies were significantly impacting the performance of students as well as capable in improving their ability to achieve the intended learning outcomes. Several studies which linked SRL to academic achievement have also identified a direct correlation between learners' SRL levels and their achievement. These findings were applied to diverse academic disciplines and at different educational levels [21]. 
Barnard, Lan, and Osland Paton [22] conducted research with public university students who enrolled in online degree programs to investigate the relationship between students ability to regulate their learning and academic achievement expressed in the form of grade point average (GPA). They found that individuals differ significantly in their academic achievement according to their SRL profile, specifically, students with low GPAs were usually associated with minimal and disorganized profiles of SRL. This finding was aligned to the conclusion made by Barnard, Paton \& Lan [23], which stated that as high self-regulation ability leads to better competence in interacting and working together with peers; as a result, it improves the performance of students in online learning.

Based on these studies, the current study hypothesized that students' self-regulated learning (SRL) ability significantly affects their academic achievement in blended learning courses.

$\boldsymbol{H}_{3}$ : Students' self-regulated learning (SRL) strategies influence academic achievement in blended learning courses.

\subsection{Objectives of the study}

This study aims to determine the causal relationships among students' self-regulated learning (SRL) strategies, peer learning, and academic achievement in the blended learning environment. To establish a structural equation model (SEM), peer learning represents the exogenous variable, while students' self-regulated learning (SRL) ability and academic achievement are endogenous variables. Specifically, the research aims to determine the influence of peer learning on students' self-regulated learning (SRL) strategies and academic achievement in blended learning courses.

\subsection{Research questions and hypotheses}

To answer the research objectives, two research questions are formulated:

- Does peer learning directly influence students' self-regulated learning (SRL) and academic achievement in blended learning courses?

- Does self-regulated learning (SRL) directly influence academic achievement in blended learning courses?

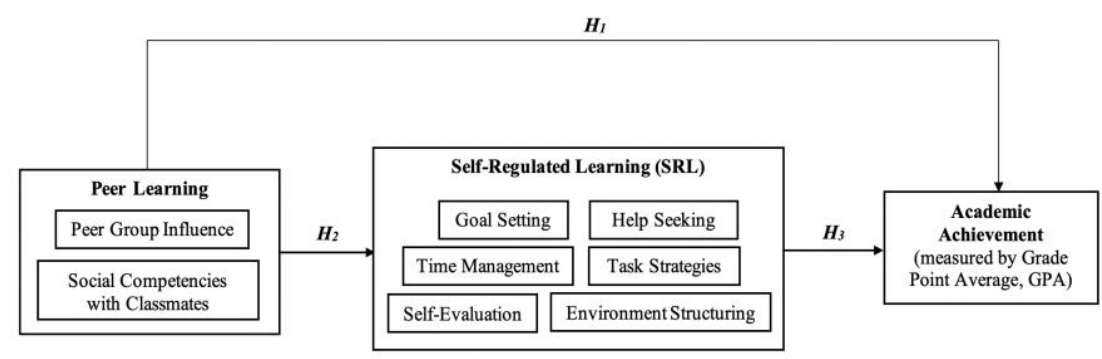

Fig. 1. Hypothesized Model of Current Research 


\section{$3 \quad$ Methodology}

\subsection{Research design}

This study aims to determine the causal relationships among students' self-regulated learning (SRL) abilities, peer learning, and academic achievement in a blended learning environment. Therefore, it adopts a correlational research design to investigate the possibility of relationships between these variables without any attempt to influence or manipulate these variables.

\subsection{Location of the study}

This study was conducted at a private university at Klang Valley. The target population for this study comprised of undergraduate students $(\mathrm{N}=7,515)$ who was taking credit-bearing courses offered in blended learning mode at a private university at Klang Valley. From the data given by the university's administration on the number of active undergraduate students as of March 2019 semester, there are approximately 7,515 students.

\subsection{Sample size}

Raosoft ${ }^{\circledR}$ online sample size calculator for SEM was also used to calculate the sample size as it is an efficient and user-friendly software. Raosoft ${ }^{\circledR}$ software suggested 366 as the minimum number of sample size needed in this study with a 5\% of the margin error and a $95 \%$ of confidence level.

\subsection{Data collection procedure}

A set of online self-reported questionnaire was designed using the SurveyMonkey.com, and the survey links were then posted in Taylor's Integrated Moodle eLearning System (TIMeS) portal, the University's official Learning Management System (LMS) in the March 2019 semester. To reduce possible bias in competency levels among learners in a particular academic discipline, a total of 45 blended courses across 15 different academic disciplines were selected, including engineering, business, engineering, biosciences, medicine, and many more.

The survey link was posted in the announcement section of each blended course 4 weeks before the end of the semester. A recruitment message was sent to instructors via email at the middle of the semester and respondents did not have any direct contact with the researcher. Data were checked for duplicate responses by comparing participating student ID, and duplicate responses were removed. The link for the survey was closed once it reaches the desired number of proportionate sample size according to the proportional stratified sampling method explained. 


\subsection{Demographic profiles of the respondents}

The intended population of this study are the students who are taking credit-bearing courses offered in blended learning mode at a private university at Klang Valley. Of the 409 respondents, only 347 were valid for data analysis and 62 respondents had to be excluded. This is due to incomplete responses with missing values, including invalid student identification number and inappropriateness of action in giving respond such as spent less than 1 minute to complete the online survey or had the monotonous pattern in answering the questionnaire. Consequently, data from 347 respondents were analysed, forming a usable case of $84.84 \%$.

The demographic characteristics of the respondents are shown in table 1. which consist of the attributes of the respondents, including gender, faculty, academic discipline, and semester. As depicted in Table 1, there were 132 (38\%) male and 215 (62\%) female respondents. Concerning the respondent's academic disciplines, the majority of the respondents came from social science $(59.7 \%$ ) programmes in which shows almost a balance group of students in terms of their field.

Table 1. Demographic Profiles of the Respondents

\begin{tabular}{|l|c|c|}
\hline \multicolumn{1}{|c|}{ Demographic Variables } & Frequency (n) & Percentage (\%) \\
\hline Gender & & \\
\hline Male & 132 & 38.0 \\
\hline Female & 215 & 62.0 \\
\hline Faculty & & 29.7 \\
\hline Business \& Law & 103 & 29.7 \\
\hline Social Sciences \& Leisure Management & 103 & 12.2 \\
\hline Health \& Medical Sciences & 42 & 28.4 \\
\hline Innovation \& Technology & 99 & 10 \\
\hline Total & 347 & \\
\hline
\end{tabular}

\subsection{Measurement and instrumentation}

In this study, data was gathered using the survey method with a set of online questionnaires. The questionnaire employed in this study was adapted from pre-existing reliable and valid multi-item instruments derived according to the literature review and objectives of the study. These adapted instruments are based on (i) Online Self-Regulated Learning Questionnaire (OSLQ) established by Barnard et al. [23], (ii) Social Competency with peers in online learning developed by Shen et al. [16], and (iii) Peer Group Influence Assessment Questionnaire (PGIAQ) developed by Uzezi \& Deya [14]. These instruments are widely used and fairly tested for their reliability and validity. Permissions have also been obtained from the authors to use and adapt their instruments for the purpose of this study. 
Table 2. Components of the questionnaire

\begin{tabular}{|l|l|c|}
\hline \multicolumn{1}{|c|}{ Section } & \multicolumn{1}{|c|}{ Section } & No. of Item \\
\hline Section A & Demographic Information \& GPA & 3 \\
\hline Section B & Peer-Learning & 14 \\
\hline Section C & Self-Regulated Learning (SRL) Strategies & 27 \\
\hline
\end{tabular}

\subsection{Measuring peer learning}

In this study, peer learning measures students' ability to learn with peers and the influence of peer groups in enhancing their academic achievements in blended learning courses. A total of 14 items were used to measure peer-learning in blended learning. 5 items were adopted from Social Competency with Peers in online learning [16] and another 9 items were adopted from Peer Group Influence Assessment Questionnaire (PGIAQ) [14]. The participants were asked to answer the questions on a 7-point Likert scale $(1=$ not at all true of me to $7=$ very true of $\mathrm{me})$.

\subsection{Measuring self-regulated learning (SRL) strategies}

In this study, Online Self-Regulated Learning Questionnaire (OSLQ) [23] has been chosen as this instrument provides a means of assessing the self-regulatory learning strategies of students in a blended learning environment. It is suitable to measure the potential application of SRL strategies in a blended learning setting. Additionally, this instrument has also been validated across two samples of learners in the online and blended learning environments respectively, and the results revealed acceptable reliability and validity as well as statistical significance.

\section{$4 \quad$ Data Analysis and Results}

\subsection{Structural equation modeling (SEM) analysis}

The structural model was used to examine and describe the direct influence of peer learning and SRL strategies on respondents' academic achievement in blended learning courses. As shown in Figure 2 and Table 3, the results of assessing the structural model fits indicated that the data fitted the model with $\chi 2 / \mathrm{df}=1.697 ; \mathrm{CFI}=0.916$; IFI $=0.917$; $\mathrm{TFI}=0.912$; and RMSEA $=0.045$. Therefore, based on the recommendation from Hair at al. [24], it is concluded that the structural model fit the Goodness-of-fit indices, which was the indication of an acceptable fit between the hypothetical model and the data collected. Consequently, further analysis can be proceeded using the structural model. 


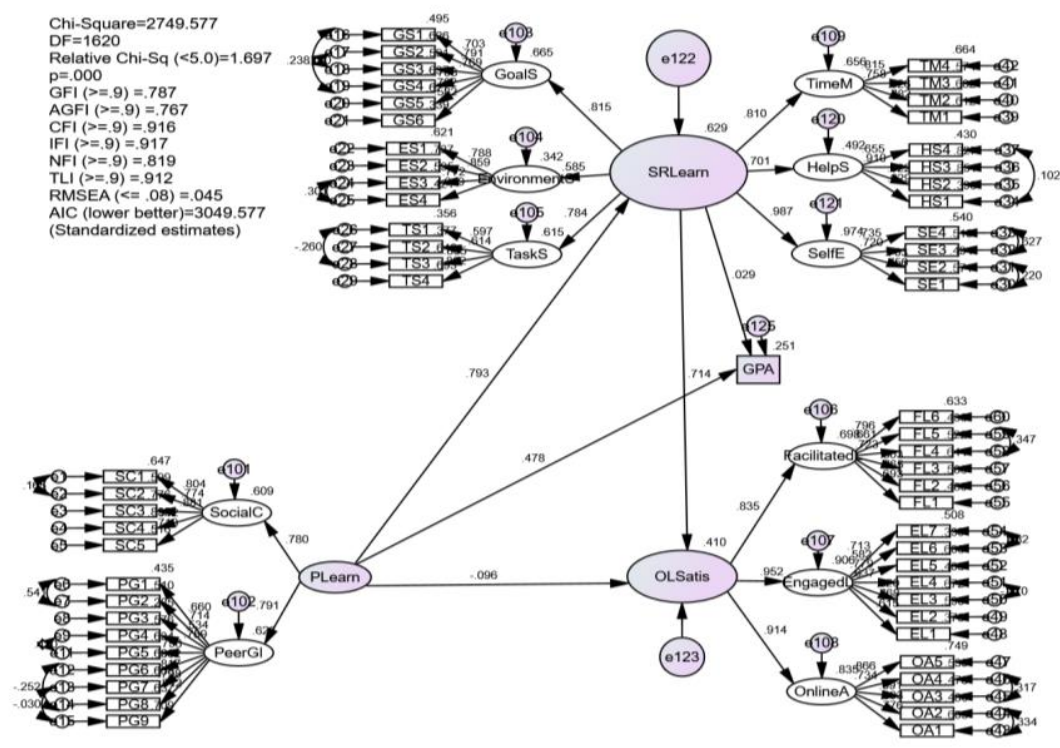

Fig. 2. The Structural Model of the Study with Standardized Regression Weights

Table 3. Goodness-of-fit Indices of Structural Model

\begin{tabular}{|l|c|c|c|c|c|c|}
\hline Goodness of fit Index & CMIN $\left(\chi^{2}\right)$ & $\chi^{2} /$ df & CFI & IFI & TLI & RMSEA \\
\hline Value & $2749.577(\mathrm{p}=0.000)$ & 1.697 & 0.916 & 0.917 & 0.912 & 0.045 \\
\hline
\end{tabular}

\subsection{The hypothesized direct effect of predictors on academic achievement}

From the structural model, the coefficient of determination $\left(\mathrm{R}^{2}\right)$ value for academic achievement was 0.251 . This indicates $25.1 \%$ of the variation in the respondents' academic achievement was explained by the variations in peer learning and their self-regulated learning (SRL) strategies. In other words, another $74.9 \%$ of the variation in academic achievement could be explained by other factors outside the scope of this study. The path coefficients and the results of examining hypothesized direct effect on academic achievement are displayed in table 4.

Table 4. The Regression Weights in the Hypothesized Direct Model on the Effect of Predictors on Academic Achievement

\begin{tabular}{|l|c|c|c|c|c|}
\hline \multicolumn{1}{|c|}{ Hypothesized Relationship } & B & S.E & $\boldsymbol{\beta}$ & C.R & $\boldsymbol{p}$ \\
\hline Peer Learning $\rightarrow$ GPA & 0.384 & 0.106 & 0.478 & 3.628 & 0.000 \\
SRL $\rightarrow$ GPA & 0.035 & 0.141 & 0.029 & 0.249 & 0.803 \\
\hline
\end{tabular}

Note: B (unstandardized regression weight); S.E. (standard error); $\beta$ (standardized regression weight); C.R. (critical ratio)

Peer learning and academic achievement: As illustrated in table 4, the results of the structural model estimation indicated that there is a significant positive relationship 
between peer learning and academic achievement $(\beta=0.478$, C.R. $=3.628, p=0.000)$. Therefore, the $\mathbf{H 1}$ was supported by statistical evidence. That is, the ability to learn from and with peers significantly influence students' academic achievement. Further, the standardized estimate of $\beta$ was 0.478 , indicating a positive relationship. It means, when peer learning goes up by 1 standard deviation, academic achievement goes up by 0.478 standard deviations.

Self-regulated learning (SRL) strategies and academic achievement: As shown in table 4 , the results of the structural model estimation depict that there was no significant relationship between SRL strategies and academic achievement in the study $(\beta=$ 0.029; C.R. $=0.249 ; p=0.803)$. Therefore, based on the structural model, the H3 was rejected, which implies that SRL does not influence academic achievement in blended learning courses at 0.05 level of significance.

\subsection{The hypothesized direct effect of peer learning on self-regulated learning (SRL) strategies}

From the structural model, the coefficient of determination $\left(\mathrm{R}^{2}\right)$ value for SRL strategies was 0.629 . This indicates $62.9 \%$ of the variation in the respondents' SRL strategies was explained by the variations in peer learning at $95 \%$ confidence level. In other words, another $37.1 \%$ of the variation in SRL strategies could be explained by other factors outside the scope of this study. The path coefficients and the results of examining hypothesized direct effect on SRL strategies are displayed in table 5.

Table 5. The Regression Weights in the Hypothesized Direct Model on the Effect of Peer Learning on Self-Regulated Learning (SRL) Strategies

\begin{tabular}{|c|c|c|c|c|c|}
\hline Hypothesized Relationship & B & S.E. & $\boldsymbol{\beta}$ & C.R. & $\boldsymbol{p}$ \\
\hline Peer Learning $\rightarrow$ SRL & 0.528 & 0.076 & 0.793 & 6.991 & 0.000 \\
\hline
\end{tabular}

Note: B (unstandardized regression weight); S.E. (standard error); $\beta$ (standardized regression weight); C.R. (critical ratio)

As depicted in table 5, the results indicated that peer learning was found to have a positive and statistically significant effect on students' SRL strategies $(\beta=0.793$; C.R. $=6.991 ; p=0.000$ ). Therefore, the $\mathbf{H} 2$ was supported by the results of structural model estimation. That is, the ability to learn from and with peers has influenced students' SRL strategies in blended learning courses. Further, the standardized estimate of $\beta$ was 0.793 , indicating a positive relationship. It means, when peer learning goes up by 1 standard deviation, self-regulated learning (SRL) strategies go up by 0.793 standard deviations. 


\section{$5 \quad$ Discussion and Conclusion}

\subsection{Discussion of findings}

The current finding regarding the positive influence of peer learning on student's academic performance was in concurrent with Uzezi and Deya [14]. Overall, peer learners associated themselves as the group which has acquired better comprehension in the key concepts, and therefore, performed better in the course as compared to those who study individually. These findings supported previous studies from Han, Chung \& Nam [25] who confirmed that peer learning improved medical students' understanding of the multidimensional structure of the human body, and led to better academic performance. Indeed, this finding confirmed Weyrich et al. [26] conclusion on the effectiveness of peer learning on improvement of students' performance.

In addition, the result clearly demonstrated that peer learning was one of the important elements to enhance students' self-regulation behaviours in the virtual learning environment, such as develop stronger friendships, better manage challenges faced in their study, as well as to set goals and organize learning in order to achieve better academic outcomes. Broadly speaking, successful peer learners employed a variety of regulatory behaviours as compared to those in the traditional teaching and learning setting.

In this line, the current study added empirical evidence to the existing blended learning studies on the role of peer learning. These results were in accordance with studies conducted by Webb, et al. [27], among others, who found that in the peer learning environment which relied upon social competency and interaction skills among peers, such learning environment played an essential role in the development of SRL for students. It was also similar to what Jeong and Chi [28] posited that when peers learn together, they influenced each other in their learning process, thus utilised SRL strategies more often to adjust their learning strategies and behaviours according to the peer learning environment.

Interestingly, there was no significant relationship between SRL and academic achievement. Although this finding was in line with the studies from Cho \& Heron [8] which reported that self-regulated learning strategies had no effect or revealed mix results on academic performance, it should be noted that there was a substantial body of literature that contradicted the current finding. A diverse population in this study may be a plausible explanation for this contradicting result. As suggested by Zimmerman [20], self-regulation is a context-specific process, the same instrument which was valid in one discipline may become invalid in another discipline. Chen [29] also reported that SRL strategies are general learning strategies, and the effectiveness of SRL might be discipline-specific. Therefore, the use of SRL to predict academic performance may differ across contexts and disciplines. 


\subsection{Implications of the study}

Implications to university's management: This study offers an insight as to how peer learning could enhance students' self-regulation behaviours, and subsequently foster the attainment of learning outcomes. The finding from this study has suggested for the university to formalise and prioritise peer learning in the context of blended learning in order to help students learn effectively. University could offer credit-bearing courses that help students to understand the importance of peer learning, and learn how to provide constructive feedback to peers When the benefits of peer learning is introduced into university's curriculum as a strategy to provide opportunities for students to develop and practice social skills, this initiative may lead to the implementation of improved practices for peer learning community, as well as to stimulate further research into the area of peer learning.

Implications to course instructors: As peer learning predicted academic achievement in blended learning courses, course instructors should ensure effective implementation of peer learning by encouraging respect, responsibility, and open discourse within their peers in the learning process. Also, instructors' monitoring efforts are essential to scaffold students in regulating their learning. This could be done by monitoring individual and group activities after assigning task to students, promoting social interaction among group members, communicating regularly with students about the learning progress, designing authentic tasks which provides opportunities for learners to learn from each other, as well as regularly check questions in the discussion boards and reply to students' online queries as soon as possible to increase their interaction with students.

\subsection{Conclusion}

The finding affirms that peer learning is an important element which enhances students' self-regulation behaviours. In the peer learning environment where students learning from each other, they need to utilise SRL strategies more often by selecting the appropriate strategy and structure the environment to make learning more effective; to develop stronger friendships, better manage challenges faced in their study; as well as to learn to control, manage, plan, set the educational goals and to evaluate the quality of their works with peers. All these behaviours are significantly associated with students' ability to regulate their learning.

This study empirically shows that peer learning has a positive impact on the blended learning courses and undergraduate students improved in their performance by peer learning. As students could benefit from peer learning and peer learning is a significant predictor of performance in the blended learning courses, educators need to develop increasingly effective methods to educate students to own strong self-discipline ability to plan and arrange their learning [30]. 


\subsection{Recommendations for future research}

Although it is a common practice in education research to use self-reported measures, some researchers found self-report response bias may result in result inaccuracy, and there is a tendency for below-average students to be most likely overreport their ability and achievements [31]. Therefore, future researchers are recommended to use system-generated data, such as log files stored in a LMS to better understand and measure students' SRL strategies and their ability to interact with others. Large amounts of real-time system-generated data are available to measure self-regulated students' learning patterns and how they interact and learn with their peers in the online learning context. By using data mining techniques with system-generated data, it is hoped that online SRL and peer learning in the virtual learning environment could be better understood, and hence, further advances in online SRL studies.

\section{Acknowledgement}

The authors would like to thank Taylor's University's Examination Centre for providing official GPAs of students during March 2019 Semester as well as the permission from Faculty of Educational Studies, University Putra Malaysia (UPM) to carry out this research at Taylor's University.

\section{$7 \quad$ References}

[1] I. E. Allen, and J. Seaman, "Online report card: Tacking online education in the United States, ” Newburyport, MA: Babson Survey Research Group, 2016.

[2] K. Krause, "Blended Learning Strategies", Griffith University, Queensland, 2008.

[3] J. Wang, "Application of Blending Learning Based on Network Learning Space in Teaching Design of Digital Art." International Journal of Emerging Technologies in Learning (iJET) [Online], 14.03 (2019): pp. 177-189. Web. 26 Oct. 2019 https://doi.org/10.3991/ijet. v14i03.10107

[4] Malaysia Online Education (e-Learning) Market Report, March, 2017. [Online]. Available: http://edtechreview.in/trends-insights/trends/2699-malaysia-online-education-elearningmarket-report

[5] C. Scott, (2015), "The Futures of Learning 3: What kind of pedagogies for the 21 st century?" UNESCO Education Research and Foresight, Paris, 2015.

[6] D. H. Schunk, and B. J. Zimmerman, Eds., Motivation and self-regulated learning: Theory, research, and applications. Oxford, UK: Routledge, 2012.

[7] P. R. Pintrich, "Multiple goals, multiple pathways: The role of goal orientation in learning and achievement," Journal of Educational Psychology, vol. 92, pp. 544-555, 2000. https:// doi.org/10.1037//0022-0663.92.3.544

[8] M.-H, Cho, \& M. L. Heron, "Self-regulated learning: The role of motivation, emotion, and use of learning strategies in students' learning experiences in a self- paced online mathematics course,' Distance Education, vol. 36, no. 1, pp. 80-99, 2015. https://doi.org/10. $\underline{1080 / 01587919.2015 .1019963}$

[9] M. Herie, "Andragogy 2.0? Teaching and Learning in the Global Classroom: Heutagogy and Paragogy," Global Citizen Digest, vol. 2, no. 2, pp. 8-14, 2013. 
[10] K. J. Topping, “Trends in peer learning,” Educational Psychology, vol. 25, pp. 631-645, 2005.

[11] M. Keppell, G. Suddaby, and N. Hard, Good practice report: technology-enhanced learning and teaching, 2011. [Online]. Available https://www.academia.edu/4405298/Good_Prac$\underline{\text { tice_Report_Technology-Enhanced_Learning_and_Teaching. https://doi.org/10.3402/rlt. }}$ v23.25728

[12] D. Boud, Moving towards autonomy, in Developing Student Autonomy in Learning, $2^{\text {nd }}$ edn. Kogan Page, London, 1998.

[13] Nasrullah, Anton, Mira Marlina, \& Widya Dwiyanti. "Development of Student WorksheetBased College E-Learning Through Edmodo to Maximize the Results of Learning and Motivation in Economic Mathematics Learning." International Journal of Emerging Technologies in Learning (iJET) [Online], 13.12 (2018): pp. 211-229. Web. 26 Oct. 2019 https://doi.org/10.3991/ijet.v13i12.8636

[14] J. G. Uzezi and G. D. Deya, "Relationship between Peer Group Influence and Students' Academic Achievement in Chemistry at Secondary School Level", American Journal of Educational Research, vol. 5, no. 4, pp. 350-356, 2017.

[15] T. Yu and J. C. Richardson, "An exploratory factor analysis and reliability analysis of the Student Online Learning Readiness (SOLR) instrument" Online Learning, vol. 19, no. 5, pp. 120- 141, 2015. https://doi.org/10.24059/olj.v19i5.593

[16] D. Shen, M. Cho, C. Tsai, and R. Marra, "Unpacking online learning experiences: Online learning self-efficacy and learning satisfaction," Internet and Higher Education, vol. 19, pp. 10-17, 2013. https://doi.org/10.1016/j.iheduc.2013.04.001

[17] E. T. Bankole and F. C. Ogunsakin, "Influence of Peer Group on Academic Performance of Secondary School Students in Ekiti State," International Journal of Innovative Research and Development, vol. 4, no. 1, pp. 324-331, 2015.

[18] X. Chen, X. Huang, L. Chang, L. Wang, and D. Li, "Aggression, social competence, and academic achievement in Chinese children: a 5-year longitudinal study," Development and Psychopathology, vol. 22, no. 3 (special issue), pp. 583-592, 2010. https://doi.org/10.1017/ $\underline{\mathrm{s} 0954579410000295}$

[19] D. H. Schunk, "Self-regulated learning: The educational legacy," Educational Psychologist, vol. 40, no. 2, pp. 85-94, 2005. https://doi.org/10.1207/s15326985ep4002_3

[20] B. J. Zimmerman, “A social cognitive view of self-regulated academic learning,” Journal of Educational Psychology, vol 81, no. 3, 329-339, 1989. https://doi.org/10.1037/0022$\underline{0663.81 .3 .329}$

[21] E. J. Lopez, K. Nandagopal, R. J. Shavelson, E. Szu, and J. Penn, "Self-regulated learning study strategies and academic performance in undergraduate organic chemistry: an investigation examining ethnically diverse students". J Res Sci Teach, vol. 50, pp. 660-676,2013. https://doi.org/10.1002/tea.21095

[22] L. Barnard, V. O. Paton, and W. Y. Lan, "Self-regulation across time of first-generation online learners," Research in Learning Technology, vol. 18, no. 1, pp. 61-70, 2010. https://doi.org/10.3402/rlt.v18i1.10752

[23] L. Barnard, W. Y. Lan, Y. M. To, V. O. Paton and S. L. Lai, "Measuring self-regulation in online and blended learning environments," Internet and Higher Education, vol. 12, pp. 16, 2009. https://doi.org/10.1016/j.iheduc.2008.10.005

[24] J. F. Hair, W. C. Black, B. J. Babim and R. E. Anderson, "Multivariate Data Analysis: A Global Perspective," seventh ed. New Jersey: Pearson Education.

[25] E. R. Han, E. K. Chung, K. I. Nam, "Peer-Assisted Learning in a Gross Anatomy Dissection Course,", PLoS ONE, vol. 10, no. 11, 2015. https://doi.org/10.1371/jounal.pone. $\underline{0142988}$ 
[26] P. Weyrich, N. Celebi, M. Schrauth, "Peer-assisted versus faculty staff-led skills laboratory training: a randomised controlled trial," Medical Education, vol. 43, pp. 113-20, 2009. https://doi.org/10.1111/j.1365-2923.2008.03252.x

[27] N. M. Webb, M. L. Franke, T. De, A. G. Chan, D. Freund, P. Shein, and D. K. Melkonian, 'Explain to your partner': Teachers' instructional practices and students' dialogue in small groups," Cambridge Journal of Education, vol. 39, no. 1, pp. 49-70, 2009. https://doi.org/ $10.1080 / 03057640802701986$

[28] H. Jeong, and M. T. H. Chi, "Knowledge convergence and collaborative learning," Instructional Science, vol. 35, pp. 287-315, 2007.

[29] C. S. Chen, "Self-regulated learning strategies and achievement in an introduction to information systems course," Information Technology, Learning, and Performance Journal, vol. 20, no. 1, pp. 11-25, 2002.

[30] Suartama, I, Punaji Setyosari, Sulthoni Sulthoni, \& Saida Ulfa. "Development of an Instructional Design Model for Mobile Blended Learning in Higher Education." International Journal of Emerging Technologies in Learning (iJET) [Online], 14.16 (2019): pp. 4-22. Web. 26 Oct. 2019 https://doi.org/10.3991/ijet.v14i16.10633

[31] J. Cole, and R. M. Gonyea, "Accuracy of self-reported SAT and ACT test scores: Implications for research," Research in Higher Education, vol. 51, no. 4, pp. 305-319, 2010. https://doi.org/10.1007/s11162-009-9160-9

\section{Authors}

Lim Chee Leong is the Director of e-learning Academy (eLA), a department under Centre For Future Learning that has been set up with the specific mandate to drive and support the implementation of blended learning at Taylor's University. He has been in the education industry for 19 years, both in teaching and administration. He has also contributed very significantly in transforming the learning and teaching of students in the University. In both 2008 and 2011, he was the recipient for Taylor's University Chairman's Award for Excellence in Teaching and in 2013, he received Taylor's University President's Award for Transformational Teaching and Learning Category. At the national level, he is the first notable individual from a private university in Malaysia to be awarded the prestigious National Academic Award (Anugerah Akademik Negara, AAN) by the Ministry of Education Malaysia for his innovative teaching methodologies.

Habibah Ab Jalil is an academician in the Faculty of Educational Studies, Universiti Putra Malaysia (UPM) since 2000. She was assigned as the lead researcher for the study of MOOC on a national level in 2016 which have a major impact on UPM and the country. Now, she is the Coordinator of Innovative Teaching and Learning Centre Of Excellence (INNOVATE) and Technology Coordinator for Putra Future Classroom (PFC), Faculty of Educational Studies, taking role in establishing and strategizing the operation and direction of the first PFC in UPM.

Aini Marina is a senior lecturer in Educational Psychology at the Department of Foundations of Education of the Faculty of Educational Studies at Universiti Putra Malaysia. Her current research interests include investigating moment-by-moment learning, measuring cognitive performance across the lifespan, evaluating collaborative 
learning processes, analyzing argumentation and reasoning, advancing ICT-driven innovation in higher education teaching and learning and promoting emergent literacy skills among underserved populations.

Wan Zuhainis Binti Saad is the Director, Academic Development \& Management Division, Ministry of Education (MOE). She was previously the Head, Department of Microbiology, Faculty of Biotechnology and Biomolecular Sciences and Deputy Director, Center of Academic Development (CADe), Universiti Putra Malaysia.

Article submitted 2019-10-26. Resubmitted 2019-11-22. Final acceptance 2019-11-23. Final version published as submitted by the authors. 